\title{
Occurrence of Stem-end Rot on Mango Fruits Caused by Lasiodiplodia theobromae in Korea
}

\author{
Sung Kee Hong ${ }^{1 *}$, Sang Yeob Lee ${ }^{2}$, Hyo Won Choi ${ }^{1}$, Young Kee Lee ${ }^{1}$, Jae-Ho Joa ${ }^{3}$ and Hongsik Shim ${ }^{1}$ \\ ${ }^{1}$ Crop Protection Division, National Academy of Agricultural Science, Rural Development Administration (RDA), Suwon 441-707, Korea \\ ${ }^{2}$ Agricultural Microbiology Division, NAAS, RDA, Suwon 441-707, Korea \\ ${ }^{3}$ Agricultural Research Center for Climate Change, National Institute of Horticultural \& Herbal Science, RDA, Jeju 690-150, Korea \\ (Received on September 22, 2011; Revised on December 16, 2011; Accepted on December 17, 2011)
}

Mango (Mangifera indica L.), an economically important fruit crop in the subtropics and tropics, was recently introduced into Korea. It is being cultivated over an area of 20 ha with an annual production of approximately 300 tons in Jeju Island. In July 2010, stem-end rots were found on fruits of mango (cv. Irwin) grown in a greenhouse in Jeju. In the early stage, the affected fruits appeared as small brown spots. As they enlarged, the lesions became circular, dark brown to black and water-soaked patches and progressed from the surface to inner part of the fruit (Fig. 1A).

Two fungal isolates were obtained from lesions on mango fruits. Cultures were initially white to smoke grey, with fluffy aerial mycelium on potato dextrose agar and became gray or black with a few medium grays in later stage (Fig. 1B). The pycnidia produced on the 14-day-old cultures (Fig. 1C) were simple, often aggregated, stromatic, ostiolate and hairy. Paraphyses within the pycnidia were hyaline, cylindrical, septate, occasionally branched. Conidiogenous cells were hyaline, thin-walled, smooth, cylindrical, holoblastic (Fig. 1D). Young conidia were hyaline, unicellular and subovoid to ellipsoid, with a granular content (Fig. 1E). Mature conidia were one-septate, dark brown, thick walled, ellipsoidal, with longitudinal striations (Fig. 1F) and measured 17.5-26.8 × 12.3-17.1 $\mu$ m (mean $22.7 \times 14.7 \mu \mathrm{m})$. No teleomorph was observed in culture. The two fungal isolates were identified as Lasiodiplodia theobromae (Pat.) Griffon \& Maubl. [Synonym: Botryodiplodia theobromaePat.] based on their morphological and cultural characteristics, and corresponded to previous description for the species (Alves et al., 2008).

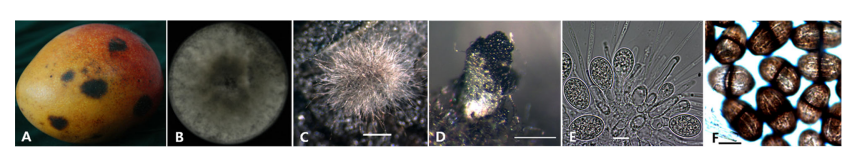

Fig. 1. A, Natural symptoms of stem-end rot on mango; B, Colony on potato dextrose agar in 7 days; $\mathrm{C}$, Pycnidia of $L$. theobromae produced on potato dextrose agar $(\mathrm{bar}=500 \mu \mathrm{m}) ; \mathrm{D}$, Conidia released from a pycnidium $(\mathrm{bar}=$ $200 \mu \mathrm{m}$ ); E, Conidiogenous cells, paraphyses and young conidia (bar $=10$ $\mu \mathrm{m}) ; \mathrm{F}$, Old conidia with thick walls and longitudinal striations ( $(\mathrm{bar}=10 \mu \mathrm{m})$.

To confirm the identification, the complete internal transcribed spacer (ITS) rDNA regions and translation elongation factor 1alpha (EF1- $\alpha$ ) of the two fungal isolates, ML1001 and ML1005 were amplified using the primers ITS1/ITS4 and EF1-688F/EF11251R as described by Alves etal.(2008) and sequenced. The resulting sequences were deposited in GenBank (Accession numbers JN542561 and JN542562 for ITS rDNA, JN542563 and JN542564 for $E F 1-\alpha)$. Sequences of reference isolates were retrieved from GenBank. A phylogenetic tree derived from combined sequences of ITS rDNA and EF1- $\alpha$ was constructed by the neighbor-joining method with Kimura's two-parameter distance model using MEGA version 5.0. In the phylogenetic tree, the present isolates placed in the same clade with $L$. theobromae in GenBank and clearly distinguished from the closely related Lasiodiplodia species, $L$. parva and L. pseudotheobromae (Fig. 2).

Pathogenicity tests were made on mango fruits. The fruits were

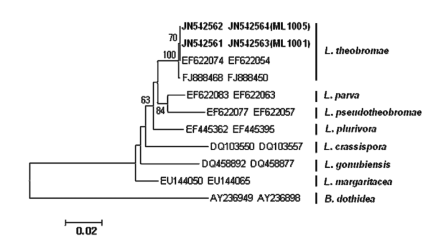

Fig. 2. A neighbor-joining tree derived from the combined sequences of ITS rDNA regions and EF1- $\alpha$ of Lasiodiplodia spp. Numbers on nodes $(>60 \%)$ represent bootstrap values $(\%)$ from 1000 replicates. A phylogenetic tree was conducted using MEGA 5.0 with kimura-two parameter model.

perforated with $3 \mathrm{~mm}$ cork borer, followed by drop-inoculated with $100 \mu \mathrm{l}$ of conidial suspensions $\left(5 \times 10^{5} \mathrm{conidia} / \mathrm{ml}\right)$. The fruits were kept in plastic box with $100 \%$ relative humidity at $25^{\circ} \mathrm{C}$ for three days. Lesions were produced on the wound-inoculated fruits. However, no symptoms developed on control fruits inoculated with sterilized distilled water. The pathogen was reisolated from inoculated fruits.

$L$. theobromae has been known to be a cosmopolitan that is associated with approximately 500 hosts including multiple genera in multiple families in different locations of the world (Punithalingam, 1976). The fungus causes cankers, dieback and stem-end rot on fruits, leaves and stems of host plants (Farr and Rossman, 2011). Alves et al. (2008) reported that the isolates originally identified as L. theobromae is divided into three species, L. theobromae, L. parva and $L$. pseudotheobromae based on their morphological features and molecular data, and there is serious doubt about Botryosphaeria rhodina (Berk. \& M. A. Curtis) Arx as teleomorph of L. theobromae. Although Physalospora rhodina Berk.\& M.A.Curtis [syn. B. rhodina] was recorded as a pathogen causing stem-end rot on Unishiu orange in Korea (Kim et al., 2009), no detailed description for the fungus was given there. To determine whether the two fungal pathogens causing stem-end rot on mango and Unishiu orange in Korea are the same species or not, further study will be needed. This is first report that $L$. theobromae causes stem-end rot on mango fruits in Korea.

\section{Acknowledgment}

This study was supported by Research Program for Agricultural Science \& Technology Development (Project No. PJ0088412012), National Academy of Agricultural Science, Rural Development Administration, Republic of Korea.

\section{References}

Alves, A., Crous, P. W., Correia, A. and Phillips, A. J. L. 2008. Morphological and molecular data reveal cryptic speciation in Lasiodiplodia theobromae. Fungal Divers. 28:1-31.

Farr, D. F. and Rossman A. Y. 2011. Fungal databases, systematic mycology and microbiology laboratory, ARS, USDA. Available from: http:// nt.ars-grin.gov/fungaldatabases.

Kim, W. G. et al. 2009. List of plant diseases in Korea. 5th edition. The Korean Society of Plant Pathology. Anyang, Korea. 853 pp.

Punithalingam, E. 1976. Botryodiplodia theobromae. C.M.I. Descr. Pathog. Fungi Bact. 519:1-3.

*Corresponding author (sukihong@korea.kr) 